
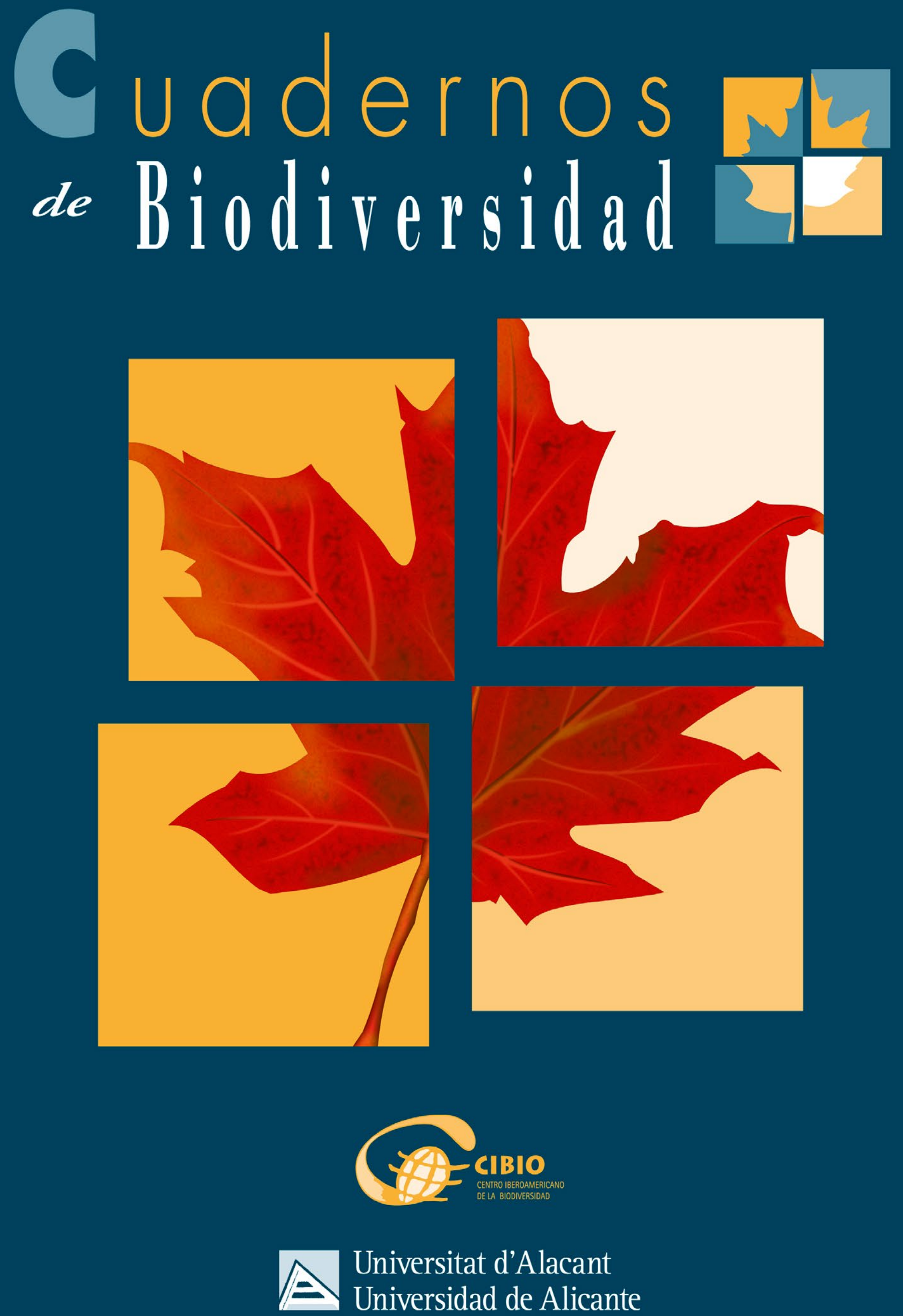


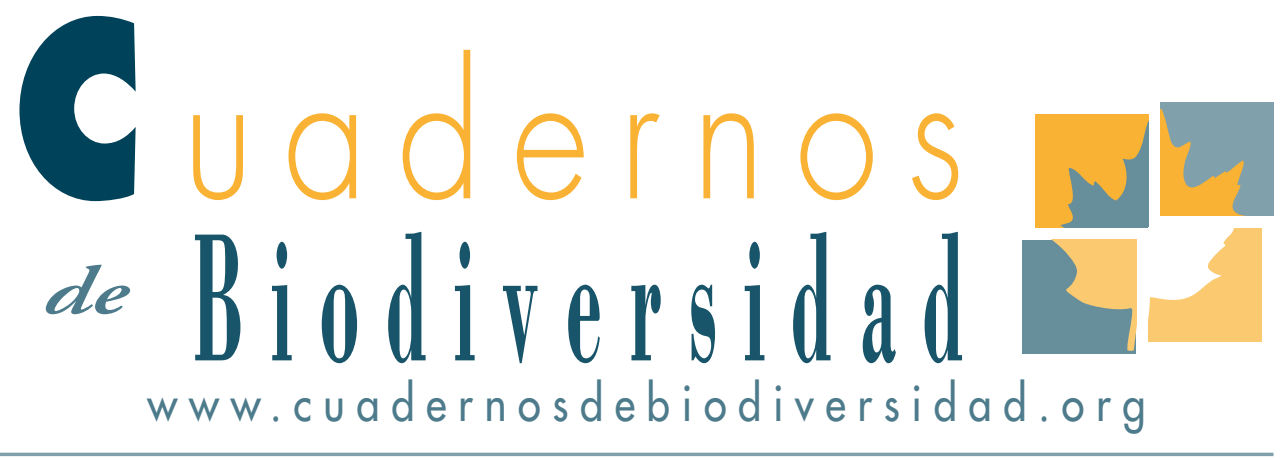

\section{Hacia una metodología para el diseño de programas de pago por servicios ambientales en manglares en México}

\section{Methodology approach towards paying for ecosystem services programs in Mexican mangroves}

\section{T García López}

UNIVERSIDAD VERACRUZANA, TGAR7O@GMAIL.COM

\section{RESUMEN}

La conservación de los manglares puede alentarse no sólo desde la tradicional estrategia normativa, sino también a través del uso de instrumentos económicos.

En este trabajo proponemos los elementos básicos de una metodológica para el diseño de instrumentos de pago por servicios ambientales para los manglares.

Empezamos por delimitar los servicios que brindan estos ecosistemas para, posteriormente, identificar las bases jurídicas dentro de los tres niveles para el diseño de un programa de este tipo.

Se define cada una de las etapas en el diseño del programa, empezando por la delimitación de la zona sobre la cual se quiere influir.

Se hace énfasis en la necesidad de identificar los servicios ambientales brindados por este ecosistema, los grupos beneficiados por éstos y el nivel en el que éstos se pueden encuadrar: municipal, estatal, nacional e internacional.

Además, se plantea la necesidad de identificar quienes deberían beneficiarse por el pago, es decir, a quien debería pagarse.

Asimismo, se enfatiza la necesidad de determinar quienes deberían pagar los servicios ambientales y cuánto deberían pagar.

Por último, el trabajo plantea campañas de comunicación e información dirigidas a los actores involucrados y de vigilancia del programa, como acciones fundamentales para el éxito del mismo.

Pallabras clave

Zonas costeras, instrumentos económicos 


\section{ABSTRACT}

The conservation of mangroves can be encouraged not only from the traditional normative strategy, but also through the use of economic instruments. This paper makes a methodology approach proposal for the design of paying for mangroves ecosystem sevices. This study starts by defining the ecosystem services provided by the mangroves and, after that, it identifies the legal bases for the design of this programs. Each of the stages in the design of the program is explained.

Emphasis is placed on the need to identify the specific environmental services provided by the ecosystem, the groups benefited by them and the level at which these can be framed: municipal, state, national and international. In addition, there is a need to clearly identify who should benefit from the payment, that is, to whom it should be paid and why. Likewise, the need to determine who should pay for environmental services and how much they should pay is emphasized. Finally, the work proposes communication and information campaigns aimed at all the actors involved and the monitoring of the program, as fundamental actions for its success.

\section{Key words}

Coastal conservation, economic instruments

\section{INTRODUCCIÓN}

Durante los últimos años se ha insistido mucho en la necesidad de valorar económicamente los servicios brindados por los manglares de México, como estrategia de vital importancia para fomentar su conservación.

Es necesario tener en cuenta que a nivel mundial México está dentro de los 4 países con mayor superficie de manglar.

Los manglares de México representan el 5\% del total mundial y colocan al país tan solo por debajo de Indonesia, Brasil y Australia (Rodríguez-Zúñiga et al., 2013).

Los manglares, a nivel global, se encuentran sometidos a una enorme presión y la superficie perdida de este ecosistema se estima que ha alcanzado un $20 \%$ durante las dos últimas décadas (FAO, 2007, p. 55).

Las zonas costeras son especialmente atractivas para el ser humano, tanto para destinarlas a vivienda como para realizar actividades turísticas, por lo que los manglares se encuentran constantemente amenazados.

El valor económico de las zonas costeras suele ser alto y, por ello, la toma de decisiones entre su conservación y su desarrollo no siempre es la adecuada.

Algunas de las especies de mangle se encuentran en la actualidad dentro de las especies protegidas por la legislación nacional por encontrarse catalogadas como especies sujetas a protección especial (NOM-059-SEMARNAT-2010, 2010). Asimismo, hay zonas de manglares que se encuentran dentro de áreas naturales protegidas, lo cual conlleva un régimen de protección especialmente estricto y, en ocasiones, hay también algunas zonas de manglar que se encuentran catalogadas como sitios Ramsar, es decir, como humedales de importancia internacional.

En México, además, el Código Penal Federal contempla como delito ambiental:

"Se impondrá pena de dos a diez años de prisión y por el equivalente de trescientos a tres mil días multa, a quien ilícitamente:

- Dañe, deseque o rellene humedales, manglares, lagunas, esteros o pantanos". (Art. 420 Bis, 1931)

A pesar de todo lo anterior y de que pudiera parecer que este conjunto de disposiciones jurídicas sería suficiente para garantizar una adecuada conservación de los manglares en México, como señalábamos en un inicio, éstos se encuentran en una situación vulnerable y, en muchas ocasiones, el nivel de contaminación al que se enfrentan es grave, siendo necesarias acciones, no sólo de protección, sino también de restauración en estos ecosistemas.

Desde el punto de vista económico, es necesario que existan incentivos para la conservación de estas áreas y los incentivos deberían beneficiar directamente a los involucrados en su protección, a sus responsables.

Los servicios ambientales son los servicios que brindan los ecosistemas, tanto de manera directa 
al ser humano como a otros elementos del medio ambiente. Han sido definidos como "Processes or materials such as clean water, energy, climate regulation, and nutrient cycling that are naturally provided by ecosystems" (Park y Allaby, 2013).

De acuerdo con la Comisión Nacional para el Conocimiento y uso de la biodiversidad de México (en adelante CONABIO):

Los procesos ecológicos de los ecosistemas naturales suministran a la humanidad una gran e importante gama de servicios gratuitos de los que dependemos. Estos incluyen: mantenimiento de la calidad gaseosa de la atmósfera (la cual ayuda a regular el clima); mejoramiento de la calidad del agua; control de los ciclos hidrológicos, incluyendo la reducción de la probabilidad de serias inundaciones y sequías; protección de las zonas costeras por la generación y conservación de los sistemas de arrecifes de coral y dunas de arena; generación y conservación de suelos fértiles; control de parásitos de cultivos y de vectores de enfermedades; polinización de muchos cultivos; disposición directa de alimentos provenientes de medios ambientes acuáticos y terrestres; así como el mantenimiento de una vasta "librería genética" de la cual el hombre ha extraído las bases de la civilización en la forma de cosechas, animales domesticados, medicinas y productos industriales"(CONABIO, s/f).

Dichos servicios disminuyen a medida que aumentan la contaminación, misma que en la mayoría de las ocasiones se encuentra relacionada con los procesos productivos; por ello, últimamente se han empezado a valorar económicamente.

El pago por servicios ambientales o ecosistémicos consiste en el otorgamiento de una retribución directa a aquéllos que se ocupan de conservar los ecosistemas que brindan una serie de servicios ambientales necesarios para el bienestar de una comunidad más o menos cercana.

Dicho pago constituye, así, una forma de internalizar, por parte de dicha comunidad, el coste de la prevención de la contaminación y también puede ser visto como una expresión del emergente principio quien se beneficia paga, de acuerdo al cual, el beneficiado por la existencia de determinado hábitat será el que debe pagar por su conservación.

Los programas de pago por servicios ecosistémicos o ambientales se han planteado hasta el momento de formas muy diferentes, que van desde las ayudas públicas enmarcadas dentro de programas oficiales, hasta mecanismos de pagos voluntarios, realizados a través de fondos.

El VII Programa General de Acción de la Unión en materia de medio ambiente, en este sentido señala:

Los recursos naturales son cada vez más escasos $y$, por eso, pueden aumentar la renta económica y los beneficios de quienes los posean o los utilicen de forma exclusiva. Para que esos recursos se utilicen de una manera más eficiente y para evitar distorsiones del mercado y generar, al mismo tiempo, ingresos públicos es necesaria una intervención pública que garantice que esas rentas no sean excesivas y que se tengan en cuenta las externalidades. En el marco del Semestre Europeo se atenderá a las prioridades medioambientales y climáticas, en particular mediante indicadores básicos cuando estas prioridades sean pertinentes a efectos de las perspectivas de crecimiento sostenible de los Estados miembros a los que se dirigen las recomendaciones. Asimismo, deben aplicarse de una forma más extensiva a nivel de la Unión y nacional otros instrumentos de mercado, tales como los pagos por servicios ecosistémicos, para incentivar la participación del sector privado y la gestión sostenible del capital natural (VII Programa General de la Unión Europea en materia de Medio Ambiente).

En este trabajo presentamos los elementos básicos para construir una propuesta metodológica para el diseño de programas de pago por servicios ambientales para los manglares. Estos elementos surgen como resultado de trabajos previos; los cuadros que se presentan como ejemplos se extraen de tesis de grado o de posgrado dirigidas por la autora.

Sobre cada uno de los pasos que se mencionan en este trabajo existe abundante literatura; nuestra intención, más que revisar a fondo cada uno de ellos, se centra en sistematizar en un documento dichas 
etapas, con la finalidad de acercarnos a una metodología para el diseño de programas de este tipo.

\section{LOS MAN GLARES Y SUS SERVICIOS AMBIENTALES}

Un humedal es una zona de transición entre los sistemas acuáticos y terrestres y, dentro de estos, se encuentran los manglares, que son zonas boscosas que prestan numerosos bienes y servicios.

Los servicios ambientales que prestan los humedales son, de acuerdo a la Secretaría de Medio Ambiente y Recursos Naturales de México (en adelante SEMARNAT), los siguientes:

- control de inundaciones

- estabilización del suelo de la zona costera

- filtración y protección del agua dulce de ríos, lagos y arroyos costeros;

- transporte de personas y materiales

- actividades acuáticas recreativas y deportivas

- dilución de contaminantes y protección de la calidad del agua, hábitat de aves y fauna silvestre

- fertilización de suelo

- incremento en el valor de la propiedad y

- valores de tipo cultural, ético, anímico y estético. (SEMARNAT, s.f)

Sanjurjo y Welsh (2005) describieron el valor de los bienes y servicios ambientales de los manglares, destacando que "para captar la totalidad de los valores que componen un ecosistema forestal, como el bosque de mangle, se utiliza el concepto del Valor Económico Total (VET). Según estos autores, el VET se conforma por dos tipos de valores:

- Valores de uso activo y

- Valores de uso pasivo. (Ibídem, p. 56)

Dentro los valores de uso pasivo los autores distinguen entre valores de herencia y valores de existencia y en los valores de uso activo, se integran los valores uso presente y los valores de uso futuro.

Asimismo, dentro de los valores de uso presente estarían:

- Valores de uso directo

- Valores de uso indirecto.
Por último, dentro de los valores de uso indirecto estarían:

- valores ambientales

- valores ecosistémicos.

En lo que se refiere a los servicios relacionados con la captura de carbono, como señala el Programa de las Naciones Unidas para el Medio Ambiente (En adelante PNUMA) (2010):

"cerca del 20\% del carbono liberado a la atmósfera proviene de ecosistemas deforestados (quema y clareo). Por ello, el conservar estos ecosistemas podría reducir significativamente los gases de efecto invernadero en la tierra. Los bosques, los humedales y las selvas son los principales sistemas que funcionan como sumidero de carbono además de proveer bienes materiales y servicios de protección”.

Además, es necesario tener en cuenta que: "los manglares liberan menos carbono que otros ecosistemas forestales. Lo anterior se debe en gran parte a que en sus suelos los promedios de descomposición son bajos y por lo tanto el almacenamiento de carbono en el suelo puede llegar a ser más alto que en los sistemas forestales de agua dulce”. (Sanjurjo \& Welsh, 2005, p. 62.)

Así, la conservación de los manglares e incluso su recuperación puede constituir una estrategia muy efectiva dentro de las políticas públicas para luchar contra el cambio climático, específicamente dentro de las estrategias tendentes a la mitigación de emisiones.

Por otra parte, como subrayan Groot et. al.: "Los ecosistemas de humedales pueden presentar algunos de los valores más elevados de los servicios ecosistémicos en comparación con otros ecosistemas, debido a la importancia de los servicios de suministro de agua limpia, mitigación de peligros naturales como son los bosques de manglar y llanuras aluviales, y almacenamiento de carbono como en turberas, manglares y marismas mareales". (Groot et al., 2012)

Además, muchos de estos servicios "son fundamentales para alcanzar los objetivos de seguridad del agua y agua para la seguridad alimentaria, seguridad 
laboral, mantenimiento de la pesca, calidad del suelo para la agricultura y una serie de beneficios culturales" (Ten et al., 2013).

Los servicios ambientales que ofrecen los humedales son: "protección costera que atenúa y/o disipa las olas y amortigua vientos. El siguiente es el de control de la erosión, favoreciendo la estabilización de los sedimentos y la retención de suelo. La protección contra crecidas con la regulación y control del caudal del agua. El suministro de agua debido a la recarga y descarga de aguas subterráneas. La purificación del agua favoreciendo la captación de nutrientes y contaminantes, así como la retención y el depósito de partículas. El secuestro de carbono que genera productividad y diversidad biológica. El mantenimiento de la pesca, la caza y las actividades de forrajeo creando un hábitat reproductivo adecuado y con diversidad biológica. Otro servicio más es el turismo, recreación, educación e investigación $y$, por último, beneficios culturales, espirituales y religiosos" (Barbier, 2011).

En lo que se refiere al cálculo de captura de carbono en manglares existen diversas metodologías. Destacan las propuestas por: Kauffman, Donato y Adame para los manglares de Bogor, Indonesia (Kauffmann Boone et. al., 2003); Adrina Yepes et. al. para los manglares de San Pedro de Montes de Oca, Costa Rica (Yepes et. al., 2016); Moreno May et. al. para los manglares de Ciudad del Carmen, Campeche, México (Moreno May et. al., 2010); Manso para los manglares de Cuba (Manso, 2001); Cerón et. al. para los manglares de Ciudad del Carmen, Campeche, México (Cerón et. al., 2010) y Karol et. al para los manglares de Cali, Colombia (Karol et. al., 2007).

Es necesario, entonces, que la conservación de los manglares se aliente no sólo desde una estratega normativa, sino también a través del uso de instrumentos económicos para que, de acuerdo al principio quien contamina paga, se fomente la internalización por parte del potencial contaminador de las externalidades o pasivos ambientales en materia de protección del capital natural.
Como señala el informe Stern, "los economistas clasifican el cambio climático de origen humano entre las "externalidades" y el clima mundial entre los "bienes públicos"” y, a diferencia de otras externalidades, ésta es de carácter global, tanto por sus causas como por sus consecuencias".

Es posible, entonces, considerar que los manglares prestan servicios ambientales globales, al igual que los bosques y deben tomarse en cuenta en la contabilidad de las emisiones de gases de efecto invernadero $y$, a nivel nacional es posible y deseable diseñar instrumentos económicos que paguen los servicios ambientales que estos brindan.

\section{BASES JURIDICAS PARA EL PAGO POR SERVICIOS AMBIENTALES AT- MOSFÉRICOS EN MÉXICO}

En México, el Plan Nacional de Desarrollo (en adelante PND) 2013-2018 (2013) incluye una estrategia sobre fortalecimiento de la política nacional de cambio climático y cuidado al medio ambiente "para transitar hacia una economía competitiva, sustentable, resiliente y de bajo carbono".

El pago por servicios ecosistémicos se ha planteado en México hasta el momento, sobre todo, para fomentar la conservación de áreas naturales como las forestales, acción ésta que permite detener la pérdida de fuentes acuíferas, la desertización y fomenta la captura de carbono, entre otros.

Sin embargo y, a pesar de que hasta el momento el pago por servicios ambientales sólo se ha planteado para la protección de áreas forestales en México, bien podría ser utilizado para la protección de otros ecosistemas, como los manglares.

A pesar de lo anterior, no existe todavía un diseño uniforme en relación a este instrumento; cuestiones como quienes son los beneficiarios de un servicio ambiental, y por ende, quienes deben pagar por dichos servicios o cuanto deben pagar y, por lo tanto cómo debe fijarse su precio, son aspectos que todavía no han sido resueltos.

Tampoco existe claridad en cuanto a qué instrumentos son más efectivos para desarrollar este instrumento ni qué estrategia de política pública adoptar. 
El PND para el período 2007-2012 (2007) planteaba la creación de dispositivos afines al mecanismo de desarrollo limpio (MDL) para el pago por servicios ecosistémicos, aunque estos a día de hoy no se han desarrollado. Hasta el momento se han elaborado programas de pago por servicios ecosistémicos, financiados en su mayoría por el sector público, enfocados al agua.

La captura de carbono se consideraba como un servicio ambiental ya en el PND 2007-2012 (Idem) y se planteaba su pago como un instrumento de mercado, el cual no necesariamente tendría que ser financiado por el sector público. De hecho, los instrumentos de mercado se supone que son financiados por los particulares y, por lo tanto, se basan en el principio de "quien contamina paga" o de "quien se beneficia paga", al contrario de lo que sucede con muchos de los esquemas actuales de pago por servicios ambientales, que funcionan como subsidios y, por ende, no están basados en estos principios.

El PND 2013-2018 señala en su estrategia 4.4.4., relacionada con la protección del patrimonio natural, entre otros, la necesidad de:

- Promover la generación de recursos y beneficios a través de la conservación, restauración y aprovechamiento del patrimonio natural, con instrumentos económicos, financieros y de política pública innovadores.

- Incrementar la superficie del territorio nacional bajo modalidades de conservación, buenas prácticas productivas y manejo regulado del patrimonio natural.

- Recuperar los ecosistemas y zonas deterioradas para mejorar la calidad del ambiente y la provisión de servicios ambientales de los ecosistemas.

Como mencionamos, ha sido muy habitual en México, al igual que en otros países, cubrir el pago por servicios ambientales a través de ayudas públicas. Así, desde el año 2003, se inició el pago por servicios ambientales en el país a través de cuatro programas (CONAFOR, s/f):

1. El programa de servicios ambientales hidrológicos (PSAH).

2. El programa para desarrollar el mercado de servicios ambientales por captura de carbono y los derivados de la biodiversidad y para fomentar el establecimiento y mejoramiento de sistemas agroforestales (PSA-CABSA).

3. El proyecto de servicios ambientales del bosque (PSAB).

4. El programa ProArbol.

En la actualidad el Programa Nacional Forestal (PRONAFOR) "apoya a los dueños y poseedores de bosques, selvas, manglares, humedales y zonas áridas, para cuidar, mejorar y aprovechar sustentablemente los recursos forestales presentes en estos ecosistemas".

De acuerdo a sus reglas de operación, en su componente de servicios ambientales, el objetivo del programa se centra en:

"Otorgar apoyos a personas propietarias o poseedoras de terrenos forestales, que de manera voluntaria deciden participar en el programa de pago por servicios ambientales, con el objeto de incorporar prácticas de buen manejo para promover la conservación y manejo sustentable de los ecosistemas, y fomentar la provisión en el largo plazo de los servicios ambientales, tales como la captación de agua, el mantenimiento de la biodiversidad y la captura y conservación del carbono, los cuales benefician a centros de población o el desarrollo de actividades productivas".

Por su parte, la Estrategia Nacional de Cambio Climático (2013) señala, en relación a los instrumentos económicos:

“...en nuestro país aún persisten esquemas de índole fiscal, financiera y económica que generan un aprovechamiento ineficiente de los recursos naturales y que, además, acentúan las diferencias económicas de la población. Avanzar hacia mejores prácticas requiere replantear dichos esquemas y crear figuras nuevas, instrumentos, regulaciones, políticas y programas para una gestión más responsable de los recursos, lo que resultará en mejores condiciones de vida para la población. Algunos ejemplos son los referentes a la conservación de los ecosistemas y las especies que los habitan, al aprovechamiento sustentable de los bosques y de la vida silvestre; al establecimiento de un control efectivo sobre las áreas naturales protegidas; a la 
generación de un valor económico de los servicios ambientales; al deslizamiento de los precios de las gasolinas; y finalmente a la implementación de esquemas tarifarios nuevos para algunos de los sectores que más agua y electricidad consumen. No obstante, todo lo anterior resulta insuficiente ante las múltiples necesidades en materia de cambio climático y de desarrollo sustentable como visión de país en general".

La Ley General de Cambio Climático (2012) señala que es facultad de la federación "Diseñar y promover ante las dependencias y entidades competentes, el establecimiento y aplicación de instrumentos económicos, fiscales, financieros y de mercado vinculados a las acciones en materia de cambio climático".

En cuanto a las competencias de los estados destacamos la que se refiere a:

"Formular, regular, dirigir e instrumentar acciones de mitigación y adaptación al cambio climático, de acuerdo con la Estrategia Nacional y el Programa, entre otras en las materias siguientes:

Preservación, restauración, manejo y aprovechamiento sustentable de los ecosistemas y recursos hídricos de su competencia”.

En lo que se refiere a los municipios, éstos tienen dentro de sus facultades:

"Formular e instrumentar políticas y acciones para enfrentar al cambio climático en congruencia con el Plan Nacional de Desarrollo, la Estrategia Nacional, el Programa, el Programa estatal en materia de cambio climático y con las leyes aplicables, entre otras en las siguientes materias:

Recursos naturales y protección al ambiente de su competencia;

Además, pueden participar en el diseño y aplicación de incentivos que promuevan acciones para el cumplimiento del objeto de la LGCC”.

La Ley General de Cambio Climático, además, cuando se refiere a los principios que deben observarse en la formulación de la política nacional de cambio climático reafirma que: "El uso de instrumentos económicos en la mitigación, adaptación y reducción de la vulnerabilidad ante el cambio climático incentiva la protección, preservación y restauración del ambiente; el aprovechamiento sustentable de los recursos naturales, además de generar beneficios económicos a quienes los implementan" (2012).

Existen, en definitiva, las bases jurídicas dentro de cada uno de los tres niveles de gobierno para el diseño de un pago por servicios ambientales y, específicamente, atmosféricos, de los manglares, los cuales se encuentran contenidos, en muchas ocasiones, dentro de la franja de la zona federal marítimo terrestre de acuerdo a lo que dispone el Reglamento para el uso y aprovechamiento del mar territorial, vías navegables, playas, zona federal marítimo terrestre y terrenos ganados al mar (Reglamento para el uso y aprovechamiento del mar territorial, vías navegables, playas, zona federal marítimo terrestre y terrenos ganados al mar,1991) y, por ello, su regulación es de competencia federal. Sin embargo, los estados y municipios, en los cuales se encuentran, tienen un buen número de competencias relacionadas con la gestión de estos importantes recursos ambientales y podrían estar involucrados en alguno de los aspectos del diseño de este instrumento económico.

Los manglares desempeñan, en definitiva, una importante labor de provisión de servicios ambientales o ecosistémicos, función ésta que no ha sido todavía reconocida en la política ambiental mexicana, encontrándose estos ecosistemas en una situación muy vulnerable, por lo que proponemos el diseńo de instrumentos de pago por los servicios que prestan, basados en el principio de "quien se beneficia paga”.

Este pago puede orquestarse de muy diferentes formas. A continuación, exponemos los pasos a seguir para el diseńo de este tipo de instrumentos.

\section{METODOLOGIAA PARA LA ELABO- RACIÓN DEL PROGRAMA}

Los pasos que se proponen para el diseño de un programa de pago por servicios ambientales provistos por los manglares y que se consideran fácilmente replicables para cualquier zona costera en la que 
exista este tipo de ecosistema son los siguientes:

\subsection{Delimitación de la zona o ecosistema sobre la que se quiere influir}

En primer lugar, es necesario delimitar claramente la zona sobre la cual se quiere influir a través del programa de pago por servicios ambientales.

Es importante destacar la importancia de utilizar, siempre que sea posible, alguna delimitación territorial preexistente, que nos facilite la obtención de información y datos para ser utilizados a lo largo del diseño del programa, habida cuenta de las carencias que en este sentido suelen existir en México.

Como habíamos mencionado anteriormente en muchas ocasiones las zonas de manglares se encuentran dentro de un área natural protegida o dentro de una zona Ramsar. En estos supuestos es muy conveniente que nuestra delimitación tome como referencia esas delimitaciones previas, ya que encontraremos datos e información muy útil para nuestro programa.

De cara a la delimitación del espacio físico sobre el cual va a operar nuestro programa de pago por servicios ambientales es importante distinguir entre:

\subsubsection{Zona de conservación y restauración}

Se trata de determinar cuál es el espacio sobre el cual son necesarias las acciones de conservación y/o de restauración más intensas, es decir la zona objetivo o zona para la cual se diseña el programa.

En esta área se encontrarán normalmente los recursos más vulnerables y asimismo los que brindan un mayor número de servicios ambientales.

Es, en definitiva, el ecosistema que justifica, por su valor o importancia ecológica, el diseño del programa de pago por servicios ambientales.

Tomando como base este espacio se identificarán la mayoría de los beneficiados por dicho programa, de acuerdo a su nivel de participación en la conservación de los recursos.

\subsubsection{Zona de aplicación del programa}

Esta zona normalmente será mucho más amplia que la anterior. Puede incluir, por ejemplo, toda la cuenca en la que se encuentre la zona de conservación o simplemente ir más allá del ecosistema a proteger, incluyendo a las demarcaciones políticas relacionadas con el ecosistema.

La zona de aplicación del programa sería la unidad económica, política, ambiental y social relacionada directamente con los manglares a proteger.

Hay quien afirma que la cuenca podría ser una unidad administrativa muy eficaz en materia ambiental y que podría ser utilizada para la gestión de otros recursos naturales, más allá de las aguas(García, 2008).

El Programa de Medio Ambiente y Recursos Naturales para período 2013-2018 establece en su objetivo número 4, relacionado con el eje "México próspero" del PND que es necesario "recuperar la funcionalidad de las cuencas y paisajes a través de la conservación, restauración y aprovechamiento sustentable del patrimonio natural"(2013).

\subsection{Identificación de los servicios ambientales}

En segundo lugar, es necesario identificar los servicios ambientales específicos brindados por el ecosistema.

Estos servicios deben ser ordenados de acuerdo a su importancia y valor y deberían, también, ser clasificados.

De acuerdo con la Comisión Nacional para el Conocimiento y uso de la biodiversidad (en adelante CONABIO):

"Los procesos ecológicos de los ecosistemas naturales suministran a la humanidad una gran e importante gama de servicios gratuitos de los que dependemos. Estos incluyen: mantenimiento de la calidad gaseosa de la atmósfera (la cual ayuda a regular el clima); mejoramiento de la calidad del agua; control de los ciclos hidrológicos, incluyendo la reducción de la probabilidad de serias inundaciones y sequías; protección de las zonas costeras por la generación y conservación de los sistemas de arrecifes de coral y dunas de arena; generación y conservación de suelos fértiles; control de parásitos de cultivos y de vectores de enfermedades; polinización de muchos cultivos; disposición directa de alimentos provenientes de medios ambientes acuáticos y terrestres; así como el mantenimiento de una vasta "librería genética" de la cual el hombre ha extraído las bases de la 
civilización en la forma de cosechas, animales domesticados, medicinas y productos industriales" (CONABIO; s/f).

Existen diferentes formas de clasificar estos servicios. Hay quien distingue entre:

- servicios intermedios y

- servicios finales. (Gómez, 2014)

También se ha distinguido entre:

- servicio ecosistémico real y

- servicio ecosistémico potencial. (Gómez, 2014)

La distinción más extendida y con la que coincidimos es la que los clasifica como:

- servicios de provisión;

- servicios de regulación y de mantención

- servicios culturales. (Haines-Young \& Potschin, 2012)

Otro concepto que ha ido ganando protagonismo durante los últimos años, muy vinculado al de capital natural y al de servicios ecosistémicos o servicios ambientales, es el de infraestructura verde. La infraestructura verde ha sido definida como:

"una red estratégicamente planificada de zonas naturales y seminaturales de alta calidad con otros elementos medioambientales, diseñada y gestionada para proporcionar un amplio abanico de servicios ecosistémicos y proteger la biodiversidad tanto de los asentamientos rurales como urbanos"( Suárez, 2011:1).

La infraestructura verde no es un término nuevo, tiene sus orígenes en la teoría de la planeación de finales del siglo XIX.

Así, ya en el año 1903 el arquitecto paisajista Law Olmsted afirmaba: "Sin importar el tamaño o el diseño de un parque, éste, por sí mismo no podrá proveer a la población de los beneficios que brinda la naturaleza en su conjunto, por tal razón se deberá pensar en un sistema de parques interconectados alrededor de los barrios" (cit. en, Benedict y McMahon, 2002).
De acuerdo con Benedict y McMahon, por infraestructura verde debemos entender: "Una red de espacios verdes interconectados que conserva los valores y funciones naturales del ecosistema a la vez que provee de beneficios a las poblaciones humanas"(Idem).

En la Unión Europea se introdujo el concepto de infraestructura verde en el año 2009, al incluirla en el Libro Blanco de la Comisión sobre la Adaptación al Cambio Climático . Según la UE, la infraestructura verde es:

“... esencial para mitigar la fragmentación y el uso insostenible de la tierra, tanto dentro como fuera de la red Natura 2000, y para hacer frente a la necesidad de mantener y restablecer los múltiples beneficios de los servicios de los ecosistemas" (COM, 2009).

También ha sido definida como:

"Green infrastructure is the network of natural and semi-natural areas, features and green spaces in rural and urban, terrestrial, freshwater, coastal and marine areas, which together enhance ecosystem health and resilience, contribute to biodiversity conservation and benefit human populations through the maintenance and enhancement of ecosystem services. Green infrastructure can be strengthened through strategic and co-ordinated initiatives that focus on maintaining, restoring, improving and connecting existing areas and features as well as creating new areas and features" (European Comission, 2010).

Es necesario tener en cuenta que dentro de lo que conocemos como infraestructura verde se encuentra tanto la infraestructura verde natural como la creada por el hombre. En este sentido, algunos autores distinguen entre:

- Infraestructura verde de naturaleza existente

Se consideran como elementos de infraestructura verde a los ecosistemas, paisajes o fenómenos naturales que anteceden o son independientes de la actividad humana. Los grandes parques, reservas o aquellos relictos de vegetación representativos por su especificidad, belleza escénica, importancia ecológica y servicios ambientales (COM, 2009). 
- Infraestructura verde de construcción humana

Se consideran todas aquellas iniciativas de manufactura o inducción que sin la presencia del ser humano no existirían; puntos de encuentro social, plazas, áreas de propagación de planta local, viveros, vegetación inducida, zonas de recarga, sistemas de infiltración, tecnologías de captación y manejo del agua, muros verdes, estanques, cisternas, camellones, jardinería urbana, aceras, zonas de tráfico lento, ciclovías, espacios peatonales, etc.

De acuerdo con la Comisión Europea:

"Invertir en infraestructura verde tiene mucha lógica desde el punto de vista económico: una única superficie de tierra puede ofrecer múltiples beneficios si sus ecosistemas están sanos. Estos ecosistemas sanos, impulsados por la diversidad de la vida que los habita, proporcionan a la sociedad una gran cantidad de bienes y servicios de gran valor e impor- tancia económica, tales como agua y aire limpios, almacenamiento de carbono, polinización, etc. También desempeñan un papel fundamental en la lucha contra el cambio climático protegiéndonos de las inundaciones y de otras catástrofes medioambientales (Comisión Europea, 2014).

Por otra parte, y como apunta Cantó López: "La Infraestructura verde se configura como un activo esencial de desarrollo sostenible en la ordenación territorial que pone en valor el componente ambiental del territorio en la planificación y en el crecimiento de las demandas de uso de suelo para usos y actividades residenciales, dotacionales o productivas, desde el principio de desarrollo territorial y urbano sostenible" (Cantó López, 2014: pp. 10-22) .

Identificar, entonces, los servicios ambientales para protegerlos y pagar por ellos conlleva que se invierta en infraestructura verde, lo cual es una alternativa eficaz y, en muchas ocasiones, menos costosa, que la inversión que supondría invertir en otro tipo de infraestructura, necesaria si dichos servicios no fuesen garantizados.

\subsection{Grupos beneficiados por los servicios ambientales}

El siguiente paso consiste en hacer un listado de los grupos beneficiados por los servicios ambientales que brinda el ecosistema sobre el cual estamos trabajando.

No debemos perder de vista que el objetivo fundamental del programa a diseñar es hacer recaer en los beneficiados por los servicios ambientales el coste de su conservación, de acuerdo al principio de "quien se beneficia paga".

La correcta delimitación de estos beneficiados, de acuerdo al listado de los servicios ambientales brindados por los manglares, es fundamental para la construcción de la propuesta, ya que serán estos grupos sobre los que recaiga el pago de acuerdo al principio de responsabilidad común pero diferenciada.

Según este principio todos somos responsables del cuidado y la protección al ambiente "pero no todos tenemos el mismo nivel o grado de responsabilidad, ya que este último depende de diferentes factores" (García, 2013, p. 251).

En esta etapa del diseńo del programa de pago por servicios ambientales es importante distinguir el nivel en el que se pueden encuadrar dichos beneficiados: municipal, estatal, nacional e internacional o global, ya que la estrategia de pago dependerá en gran medida de dichos niveles, mismos que nos darán, asimismo, las bases legales necesarias para el diseño de este instrumento.

Las bases legales, entonces, sobre las cuales profundizaremos más adelante, tendrán relación con el nivel en el que se encuentre aquéllos sobre los que recaerá el pago.

Asimismo, es básico asociar cada servicio ambiental específico con el o los beneficiados por éste.

Un ejemplo de lo anterior podemos verlo en el siguiente cuadro extraído de una tesis de grado dirigida por la autora de este trabajo en la cual se hace una propuesta de programa de pago por servicios ambientales para el Sistema Lagunar de Alvarado en el estado de Veracruz, México y en el 
cual se identifican los servicios ambientales y para cada uno de ellos se delimitan los beneficiados por éste, haciendo énfasis en si dichos beneficiados se encuentran en el nivel local (municipio dentro de los cuales se encuentra la zona de conservación, estatal (estado federal dentro de los cuales se encuentran los beneficiados, aunque no se sitúen en los municipios de la zona de conservación), nacional o internacional (Ricaño, 2017, p.94):

Tabla 1: Beneficiados por los Servicios Ambientales de los manglares de Alvarado

\begin{tabular}{|c|c|c|c|c|}
\hline \multirow[t]{2}{*}{ Servicio Ambiental } & \multicolumn{4}{|c|}{ Grupos Beneficiados } \\
\hline & Local & Estatal & Nacional & Internacional \\
\hline $\begin{array}{l}\text { Protección contra mareas } \\
\text { y control de inundaciones }\end{array}$ & $\begin{array}{l}\text { 130.277 habitantes } \\
\text { de los municipios* } \\
\text { (Directo) }\end{array}$ & & & \\
\hline $\begin{array}{c}\text { Acumulación de } \\
\text { sedimentos y formación } \\
\text { de suelos }\end{array}$ & $\begin{array}{c}130.277 \text { habitantes } \\
\text { de los municipios* } \\
\text { (Directo) }\end{array}$ & & & \\
\hline $\begin{array}{l}\text { Zona de crianza, refugio y } \\
\text { alimentación de especies }\end{array}$ & $\begin{array}{l}\text { Personal ocupado total. } \\
\text { Sector 11: pesca y } \\
\text { acuicultura. } \\
\text { 2.739 personas en los } \\
\text { municipios* } \\
\text { (INEGI, 2010) } \\
\text { (Directo) }\end{array}$ & & & \\
\hline Belleza escénica & $\begin{array}{c}\text { 130.277 habitantes de } \\
\text { los municipios* } \\
\text { (Indirecto) } \\
\text { Empresas turísticas } \\
\text { (Directo) }\end{array}$ & $\begin{array}{l}\text { Turistas del } \\
\text { estado de } \\
\text { Veracruz } \\
\text { (Directo) }\end{array}$ & $\begin{array}{l}\text { Turistas del país } \\
\text { (Directo) }\end{array}$ & $\begin{array}{l}\text { Turistas } \\
\text { del mundo } \\
\text { (Directo) }\end{array}$ \\
\hline Producción de alimentos & $\begin{array}{l}\text { 130.277 habitantes } \\
\text { de los municipios* } \\
\text { (Directo) }\end{array}$ & $\begin{array}{c}\text { Habitantes } \\
\text { del estado } \\
\text { que adquieren } \\
\text { alimentos } \\
\text { provenientes de } \\
\text { la pesca en el } \\
\text { sitio } \\
\text { (Indirecto) } \\
\end{array}$ & $\begin{array}{l}\text { Habitantes de } \\
\text { otros estados } \\
\text { donde llegue } \\
\text { el comercio de } \\
\text { especies para } \\
\text { alimentación } \\
\text { (Indirecto) }\end{array}$ & \\
\hline $\begin{array}{l}\text { Hábitat para poblaciones } \\
\text { humanas }\end{array}$ & $\begin{array}{c}96 \text { personas en el área } \\
\text { de manglar } \\
\text { (Directo) }\end{array}$ & & & \\
\hline $\begin{array}{c}\text { Control de } \\
\text { contaminación y } \\
\text { mejoramiento de la } \\
\text { calidad del agua }\end{array}$ & $\begin{array}{l}\text { 130.277 habitantes de } \\
\text { los municipios* }\end{array}$ & & & \\
\hline $\begin{array}{l}\text { Producción de oxígeno } \\
\text { y captura de dióxido de } \\
\text { carbono }\end{array}$ & $\begin{array}{l}\text { 130.277 habitantes de } \\
\text { los municipios* }\end{array}$ & $\begin{array}{l}\text { A pesar de c } \\
\text { personas benefi }\end{array}$ & $\begin{array}{l}\text { e no hay número } \\
\text { adas, este servicio } \\
\text { internacional. }\end{array}$ & $\begin{array}{l}\text { specífico de } \\
\text { ene un alcance }\end{array}$ \\
\hline
\end{tabular}

*Municipios: Alvarado, Tlalixcoyan, Ignacio de la Llave, Acula, Tlacotalpan e Ixmatlahuacan. 
En ocasiones los beneficiados están muy difuminados, especialmente a medida que aumenta la escala o ámbito y, por lo tanto, es normal que a mayor escala menores serán los servicios ambientales asociados.

\subsubsection{Beneficios directos vs. Beneficios indi- rectos}

También es importante distinguir en esta etapa entre beneficios directos e indirectos, puesto que es deseable que los servicios ambientales sean pagados, al menos en un principio, por los beneficiados directos, aunque haya otros beneficiados indirectamente por estos servicios.

A medida que este tipo de esquemas permeen en una sociedad sería deseable que todos los beneficiados (directa o indirectamente) por un servicio ambiental pagasen éste, aunque, lógicamente, lo hagan en base al principio de responsabilidad común pero diferenciada, como ya hemos mencionado.

\subsection{Identificación de los propietarios o posee-} dores de los recursos contenidos en el ecosistema

En cuarto lugar, es necesario determinar quiénes son los propietarios o poseedores de los recursos que brindan los servicios ambientales, ya que estos serán quienes reciban el pago por conservar o restaurar los manglares, permitiendo y garantizando, así, que este ecosistema siga brindando los servicios ambientales o ecosistémicos que se busca garantizar.

Es necesario tomar en cuenta que, en el caso de los manglares, lo habitual es encontrarnos con diferentes regímenes de "tenencia de la tierra". Es habitual que existan tanto terrenos públicos como privados, ejidatarios (propiedad comunal), propietarios, poseedores (entre ellos, asentamientos irregulares), concesionarios (existen concesiones en la Zona Federal Marítimo Terrestre para llevar a cabo actividades productivas: hoteles, restaurantes...); además de que el mismo manglar puede y suele estar sobre espacios que se encuentran, en ocasiones, dentro de la zona federal marítimo terrestre y, en otras, fuera de ésta, con las consecuentes diferencias en los regímenes jurídicos aplicables.

Esta delimitación de propietarios o poseedores debe servir para identificar a quienes serán bene- ficiados por el programa, es decir, a quienes se les pagará por realizar o dejar de realizar acciones de conservación de los manglares, garantizando, así, la provisión de los servicios ambientales.

También deberíamos incluir aquí a grupos involucrados en el uso del manglar, por ejemplo a grupos de pescadores que, tradicionalmente han realizado actividades de utilización del recurso y que el programa puede plantear modificar o limitar.

\subsection{Construcción de escenarios de conserva-} ción y su relación con los servicios ambientales

El quinto paso necesario para una propuesta de este tipo se centra en la construcción de unos escenarios hipotéticos de conservación de los recursos de la zona.

Estos escenarios servirán para, posteriormente, establecer los objetivos del programa, mismos que serán la base para el contrato de pago por servicios ambientales entre los beneficiados y quienes pagan dichos servicios.

La construcción de escenarios es muy utilizada para exponer alternativas acerca de las consecuencias de la acción o de la inacción y existen múltiples técnicas para ello.

Estos "Cumplen un papel práctico instrumental que permite avanzar en un ámbito donde la situación de conocimiento no permite realizar modelos detallados" (Gutman, 1995).

De acuerdo con Rasmussen (2011) es recomendable el uso de escenarios cuando se presenten las siguientes condiciones:

- Complejidad;

- Incertidumbre;

- Necesidad de combinar perspectivas de corto y largo plazo;

- Disponibilidad de recursos, responsabilidad y compromiso para la transformación de sistemas.

Dichas proyecciones o escenarios pueden establecerse a mediano o largo plazo.

Es recomendable hacerlas a mediano plazo: 20 o 30 ańos, tiempo que se considera adecuado para observar cambios en un ecosistema con una política de conservación adecuada.

Se propone, en términos generales, la construc- 
ción de tres escenarios: el primero de ellos, al que podríamos llamar "pesimista", el cual tomaría como base un período de aproximadamente 30 años atrás, caracterizado normalmente (sobre todo en la primera mitad) por la inacción y, por ende, de considerable pérdida de manglar.

El segundo escenario, denominado "intermedio" podría construirse tomando como base los niveles de pérdida de manglar de los últimos cinco años (de los cuales hay datos), de tal forma que la proyección reflejaría la tendencia actual y, por último, el escenario optimista, que plantea una mejora en el nivel de conservación, fruto del programa de pago por servicios ambientales y, por lo tanto, sería el que ayudaría a que el ecosistema siga brindando dichos servicios e incluso los amplíe.

\subsection{Objetivos del programa de pago por ser- vicios ambientales}

Después de haber construido estos escenarios hipotéticos y con la finalidad de lograr el más optimista de ellos deben plantearse los objetivos del programa de pago por servicios ambientales. Cada objetivo debe asociarse a un servicio ambiental específico.

Será necesario distinguir entre objetivos de conservación y objetivos de restauración y asociar plazos a estos objetivos.

Los objetivos deberán conllevar una serie de acciones e identificar y asociar a cada una de las acciones un grupo o varios de personas. Como ejemplo de lo anterior, tenemos el siguiente cuadro, tomado de la anterior tesis citada: (Ricaño, 2017, p.111):

Tabla 2: Servicios ambientales; objetivos a cumplir; quienes realizan las acciones por las que reciben un pago y los que realizan acciones complementarias

\begin{tabular}{|c|c|c|c|}
\hline Servicio Ambiental & Objetivos & $\begin{array}{l}\text { Quien debe realizar } \\
\text { las acciones y recibir un } \\
\text { pago por ello }\end{array}$ & $\begin{array}{c}\text { Acciones } \\
\text { complementarias }\end{array}$ \\
\hline $\begin{array}{l}\text { Protección contra mareas } \\
\text { y control de inundaciones }\end{array}$ & $\begin{array}{l}\text {-Reforestación de áreas } \\
\text { que hayan sufrido tala } \\
\text { excesiva. } \\
\text {-Protección en zonas con } \\
\text { manglar conservado. }\end{array}$ & $\begin{array}{c}\text {-Ejidatarios y comuneros. } \\
\text {-Posesionarios. } \\
\text {-Propietarios privados. }\end{array}$ & Concesionarios \\
\hline $\begin{array}{c}\text { Acumulación de } \\
\text { sedimentos y formación } \\
\text { de suelos }\end{array}$ & $\begin{array}{l}\text {-Reforestación de áreas } \\
\text { que hayan sufrido tala } \\
\text { excesiva. } \\
\text {-Protección en zonas con } \\
\text { manglar conservado. }\end{array}$ & $\begin{array}{c}\text {-Ejidatarios y comuneros. } \\
\text {-Posesionarios. } \\
\text {-Propietarios privados. }\end{array}$ & Concesionarios \\
\hline $\begin{array}{l}\text { Zona de crianza, refugio y } \\
\text { alimentación de especies }\end{array}$ & $\begin{array}{l}\text {-Establecer periodos de } \\
\text { veda estrictos. } \\
\text {-Organizar un grupo de } \\
\text { vigilancia. } \\
\text {-Restringir la pesca de } \\
\text { especies en número } \\
\text { comprometido. }\end{array}$ & $\begin{array}{l}\text { Equipo de trabajo } \\
\text { de los propietarios, } \\
\text { ejidos, comunidades, } \\
\text { posesionarios }\end{array}$ & Gobiernos municipales \\
\hline Belleza escénica & $\begin{array}{c}\text {-Recolección periódica de } \\
\text { basura dentro del manglar, } \\
\text { en las orillas de las lagunas } \\
\text { y dentro de ellas. }\end{array}$ & Pescadores & $\begin{array}{c}\text {-Gobierno municipales } \\
\text {-Habitantes de los } \\
\text { municipios }\end{array}$ \\
\hline Producción de alimentos & $\begin{array}{l}\text {-Establecer periodos de } \\
\text { veda estrictos. } \\
\text {-Organizar la vigilancia. } \\
\text {-Restringir la pesca de } \\
\text { especies en número } \\
\text { comprometido. }\end{array}$ & $\begin{array}{l}\text { Equipo de trabajo } \\
\text { de los propietarios, } \\
\text { ejidos, comunidades, } \\
\text { posesionarios }\end{array}$ & Gobiernos municipales \\
\hline
\end{tabular}




\begin{tabular}{|c|c|c|c|}
\hline $\begin{array}{c}\text { Hábitat para poblaciones } \\
\text { humanas }\end{array}$ & $\begin{array}{c}\text {-Establecer reglas de uso } \\
\text { y mantenimiento del } \\
\text { manglar. }\end{array}$ & \multicolumn{2}{|c|}{$\begin{array}{l}\text { Este es un servicio que no tiene que ser necesariamente } \\
\text { pagado. El establecimiento de reglas de uso y } \\
\text { mantenimiento del manglar tiene que ser respetado } \\
\text { por todos y no representa un costo. }\end{array}$} \\
\hline $\begin{array}{c}\text { Control de contaminación } \\
\text { y mejoramiento de la } \\
\text { calidad del agua }\end{array}$ & $\begin{array}{l}\text {-Reducir la emisión } \\
\text { de contaminantes } \\
\text { provenientes de río arriba. } \\
\text {-Análisis periódicos de } \\
\text { calidad del agua en el } \\
\text { Sistema Lagunar. }\end{array}$ & $\begin{array}{c}\text {-Ejidatarios y comuneros. } \\
\text {-Posesionarios. } \\
\text {-Propietarios privados. }\end{array}$ & $\begin{array}{l}\text { Empresas e industrias. } \\
\text { Universidad Veracruzana } \\
\text { o instituciones de } \\
\text { investigación. }\end{array}$ \\
\hline $\begin{array}{l}\text { Producción de oxígeno } \\
\text { y captura de dióxido de } \\
\text { carbono }\end{array}$ & $\begin{array}{c}\text {-Reforestación de áreas } \\
\text { que hayan sufrido tala } \\
\text { excesiva. } \\
\text {-Protección en zonas con } \\
\text { manglar conservado. }\end{array}$ & $\begin{array}{c}\text {-Ejidatarios y comuneros. } \\
\text {-Posesionarios. } \\
\text {-Propietarios privados. }\end{array}$ & Concesionarios \\
\hline
\end{tabular}

\subsection{Identificación de los beneficiados por el pago}

La siguiente etapa para el diseño del programa de pago por servicios ambientales se centra en identificar claramente quienes deberían beneficiarse por el pago, es decir, a quien debería pagarse y porqué. Estos beneficiados por el pago son quienes deberían llevar a cabo las acciones de prevención, conservación y/o restauración necesaria para lograr los objetivos del programa.
Éste es uno de los aspectos centrales y más complicados en un programa de este tipo.

Es conveniente agrupar a los beneficiarios por sectores, ordenándolos por importancia, es decir, priorizando a aquéllos en una situación más vulnerable y, por lo tanto, a los que se considera necesario dar prioridad en el pago.

La tabla siguiente nos muestra un ejemplo de cómo organizar o dividir a los grupos beneficiados por el pago (Ricaño, 2017, p.110):

Tabla 3: Beneficiados por el pago de los Servicios Ambientales en el Sistema Lagunar de Alvarado

Grupo 1
Personas con terrenos con
manglar:
Ejidos y comunidades:
-Alvarado: 19
-Tlalixcoyan: 56
-Ignacio de la Llave: 30
-Acula: 9
-Tlacotalpan: 19
-Ixmatlahuacan: 8
Posesionarios:
-Alvarado: 764
-Tlalixcoyan: 874
-Ignacio de la Llave: 572
-Acula: 140
-Tlacotalpan: 51
-Ixmatlahuacan: 61
Propietarios privados

\section{Grupo 2}

Equipo de trabajo de los propietarios, ejidos, comunidades y posesionarios para la protección de la zona de crianza, refugio y alimentación de especies, que a su vez aseguran la producción de alimentos.

\section{Grupo 3}

Pescadores 


\subsection{Definición de acciones complementarias}

$\mathrm{Al}$ mismo tiempo deben incluirse las acciones complementarias que deberían ser realizadas por algún grupo o sector, aunque estos no sean pagados por ello, por ejemplo: el gobierno o gobiernos municipales podrían asumir labores de vigilancia o de coordinación de alguna comisión integrada por diferentes sectores para la difusión del programa; los pescadores podrían asumir ciertas acciones de limpieza, etc.

\subsection{Identificación de los "obligados" a pagar y del monto del pago}

El paso siguiente consiste en determinar quienes deberían pagar los servicios ambientales (de acuerdo a la información relativa a los beneficiados expuesta previamente) y cuánto deberían pagar. Este último aspecto, es, quizá, junto al de la identificación de los grupos beneficiados por el pago, el más complicado en una propuesta de este tipo, pues no es fácil valorar económicamente los recursos naturales.

Existen, ya, múltiples metodologías que intentan valorar algunos de los servicios ambientales de los manglares, los cuales pueden ser utilizados para una propuesta de este tipo.

De acuerdo al cálculo que resulte de cada uno de los servicios y los directamente beneficiados por estos tendríamos que obtener la cantidad a pagar.

Es habitual, cuando se aplica este método, obtener unos resultados que resultan muy elevados para realizar una propuesta de pago realista y acorde al nivel de ingresos de la zona, por lo que se puede elegir dividir el programa en etapas de aplicación, de tal forma que en una primera etapa se elija pagar sólo alguno de los servicios ambientales brindados por el ecosistema y en etapas subsecuentes, dependiendo del impacto que haya tenido el programa sobre la conservación de recursos naturales, otros.

Según algunos autores "es necesario valorar únicamente aquellos servicios que son directamente consumidos por el ser humano para evitar sobrestimar su valor" (Haines-Young \& Potschin, 2012).

Calderón (2009) cita en su trabajo diversos estudios que han tratado de calcular el aporte monetario que los ecosistemas costeros brindan a la economía mundial. Menciona a Achayra y colaboradores, quienes calcularon que la producción pesquera de los manglares es de más de US $\$ 1.500$ por hectárea al año; mientras Aburto, en 2008, afirmó que el valor de los servicios que los manglares proveen a las pesquerías es de aproximadamente US $\$ 37.500$ por hectárea al año (Ricaño, 2017).

Otro servicio es la protección de costas de las tormentas, ciclones y tsunamis, que entrarían en los servicios de protección marina y costera. Estos servicios tiene un valor a nivel mundial de US\$3.000 por hectárea (Calderón et al., 2009). En cuanto a los servicios de captura de carbono, Teutli, et al. (2014) señalan que "los manglares generan unos 130.000 pesos mexicanos anuales por cada hectárea que se conserva, esto sin considerar los beneficios de regulación del clima”.

En cuanto al valor económico anual de los manglares se ha calculado con base en los productos y servicios que proporcionan y la cifra va desde los 200.000 a los 900.000 pesos mexicanos por hectárea (Herzig, 2009). Mientras que Agraz Hernández el al. (2008) estiman que el turismo asociado a manglares brinda un valor económico que está entre los 10.000 y los 125.000 dólares por hectárea al año.

Para establecer el precio que la población pagará hay que tomar en cuenta el salario mínimo vigente en México, que es de 80 pesos diarios. Si se pone una cuota de 50 pesos mensuales para el pago por servicios ambientales, ésta representa el 2.08\% del salario de los habitantes. La cuota a pagar puede ser incluida en los recibos de agua mensuales, como pago voluntario por servicios ambientales.

Pasando a los turistas, éstos pagarán el servicio de belleza escénica a través de una cooperación voluntaria en el momento de la visita. Se puede hacer un promedio para obtener la cantidad de turistas que visitan la zona al año, que será utilizada para estimar la cantidad de dinero que se puede recaudar por este grupo que hará un pago por servicios ambientales.

Por otro lado, las empresas privadas podrían realizar un pago voluntario anual.

En la siguiente tabla se muestra un ejemplo de distribución del pago por servicios ambientales para el Sistema Lagunar de Alvarado tomada de la tesis antes mencionada (Ricaño, 2017). 
Tabla 4: Servicios ambientales: ¿quién recibe el pago, quién lo efectúa y cuál es el monto de dicho pago?

\begin{tabular}{|c|c|c|c|c|}
\hline Servicio Ambiental & $\begin{array}{c}\text { Acciones } \\
\text { Complementarias }\end{array}$ & $\begin{array}{c}\text { ¿Quién recibe el } \\
\text { pago? }\end{array}$ & ¿Quién da el pago? & $\begin{array}{c}\text { ¿Cuánto se va a } \\
\text { pagar? }\end{array}$ \\
\hline $\begin{array}{l}\text { Protección contra } \\
\text { mareas y control de } \\
\text { inundaciones }\end{array}$ & Concesionarios & $\begin{array}{l}\text { Ejidatarios, } \\
\text { comuneros, } \\
\text { posesionarios } \\
\text { y propietarios } \\
\text { privados }\end{array}$ & $\begin{array}{c}\text { Habitantes de los } 6 \\
\text { municipios }\end{array}$ & $(13,33 \%)$ \\
\hline $\begin{array}{c}\text { Acumulación } \\
\text { de sedimentos y } \\
\text { formación de suelos }\end{array}$ & Concesionarios & $\begin{array}{c}\text { Ejidatarios, } \\
\text { comuneros, } \\
\text { posesionarios } \\
\text { y propietarios } \\
\text { privados }\end{array}$ & & \\
\hline $\begin{array}{l}\text { Zona de crianza, } \\
\text { refugio y } \\
\text { alimentación de } \\
\text { especies }\end{array}$ & $\begin{array}{l}\text { Gobiernos } \\
\text { municipales }\end{array}$ & $\begin{array}{l}\text { Equipo de trabajo } \\
\text { de los propietarios, } \\
\text { ejidos, comunidades, } \\
\text { posesionarios }\end{array}$ & & $(12,5 \%)$ \\
\hline Belleza escénica & $\begin{array}{c}\text { Gobierno municipal } \\
\text { y habitantes de los } \\
\text { municipios. }\end{array}$ & Pescadores & Turistas & $(35 \%)$ \\
\hline $\begin{array}{l}\text { Producción de } \\
\text { alimentos }\end{array}$ & $\begin{array}{l}\text { Gobiernos } \\
\text { municipales }\end{array}$ & $\begin{array}{l}\text { Equipo de trabajo } \\
\text { de los propietarios, } \\
\text { ejidos, comunidades, } \\
\text { posesionarios }\end{array}$ & & $(12,5 \%)$ \\
\hline $\begin{array}{l}\text { Hábitat para } \\
\text { poblaciones } \\
\text { humanas }\end{array}$ & - & & & \\
\hline $\begin{array}{c}\text { Control de } \\
\text { contaminación y } \\
\text { mejora de la calidad } \\
\text { del agua }\end{array}$ & $\begin{array}{l}\text { Empresas e } \\
\text { industrias }\end{array}$ & $\begin{array}{l}\text { Ejidatarios, } \\
\text { comuneros, } \\
\text { posesionarios } \\
\text { y propietarios } \\
\text { privados. }\end{array}$ & $\begin{array}{c}\text { Empresas: } \\
\text { cervecería, papelera } \\
\text { e ingenio azucarero. }\end{array}$ & $(13,33 \%)$ \\
\hline $\begin{array}{c}\text { Producción de } \\
\text { oxígeno y captura de } \\
\text { dióxido de carbono }\end{array}$ & Concesionarios & $\begin{array}{c}\text { Ejidatarios, } \\
\text { comuneros, } \\
\text { posesionarios } \\
\text { y propietarios } \\
\text { privados. }\end{array}$ & Mercado de carbono & $(13,33 \%)$ \\
\hline
\end{tabular}

\subsection{1. ¿̨Sobre quiénes recaerá el pago?}

Es conveniente agrupar a los sectores sobre los cuales consideramos deberá recaer el pago. Estos sectores tendrán que desprenderse de los beneficiados por los servicios ambientales que brinda el ecosistema y se sugiere ordenarlos o aglutinarlos de acuerdo a los beneficios o servicios recibidos por la conservación de los manglares, tomando en cuenta si son beneficiados directa o indirectamente y tomando en cuenta, también, su capacidad económica.
Por ejemplo: habitantes del o de los municipios en los que se encuentran los manglares; turistas que visitan la zona; empresas privadas relacionadas de alguna forma con el ecosistema.

Durante los últimos años se han desarrollado diferentes iniciativas relacionadas con el desarrollo de diferentes mercados de carbono y es muy conveniente intentar atraer o incorporar al programa compradores de ese servicio de captura de carbono, 
a través de la venta de créditos o certificados.

Para ello es importante determinar la cantidad de carbono que captura el área.

\subsection{Bases jurídicas para solicitar el pago:} Instrumentos obligatorios vs instrumentos voluntarios

Las bases legales sobre las cuales descansará el programa para su puesta en marcha tendrán relación, necesariamente, con el nivel en el que se encuentren aquéllos sobre los que recaerá el pago.

Por ejemplo: si consideramos que los habitantes de los municipios donde se encuentra el ecosistema deben pagar por el servicio de control de inundaciones, entonces, para el pago de dicho servicio, deberíamos buscar las bases jurídicas en el derecho municipal.

También es importante tener en cuenta que los pagos pueden exigirse de manera obligatoria, por ejemplo, a través de un gravamen o de manera voluntaria, a través de aportaciones previamente establecidas.

Para llevar a cabo los pagos desde los pagadores hacia el fondo desde el cual se harán posteriormente los pagos a los beneficiados existen varias opciones.

Para empezar, es necesaria la constitución de un fondo económico, que puede ser público, privado o mixto. Lo más conveniente, a nuestro juicio, sería la constitución de un fondo mixto que pueda nutrirse tanto de aportaciones públicas como privadas.

Los fondos ambientales son mecanismos financieros que facilitan la puesta en marcha de políticas y acciones de protección del medio ambiente. Actúan "complementando las acciones gubernamentales y fomentando la participación de la sociedad civil en la conservación de los recursos naturales, conciliando las demandas ambientales globales con las prioridades y realidades nacionales" (Red de Fondos Ambientales de América Latina y el Caribe, 1999).

Lo más habitual es que este tipo de fondos se establezcan como fundaciones o fideicomisos privados, como organizaciones no gubernamentales o como sociedades de responsabilidad limitada sin fines de lucro y habitualmente son administrados por un consejo de administración con miembros del sector público y privado (Idem).
Los instrumentos financieros en materia ambiental son aquéllos que buscan brindar recursos financieros para la protección y /o restauración del medio ambiente. El VII Programa General de Acción de la Unión en materia de medio ambiente, en este sentido, dispone:

"A fin de asegurar inversiones para la política en materia de medio ambiente y clima y hacer frente a las externalidades medioambientales, el VII PMA garantizará que, para 2020:

…

b) haya aumentado la financiación procedente del sector privado y del público para gastos relacionados con el medio ambiente y el clima;

c) el valor del capital natural y los servicios ecosistémicos, así como el coste de su degradación, se hayan evaluado adecuadamente y tenido en cuenta en la toma de decisiones políticas y en las inversiones (VII Programa General de la Unión Europea en materia de medio ambiente)".

Para conseguir lo anterior establece que es necesario:

"facilitar el acceso a fondos e instrumentos financieros innovadores a favor de la ecoinnovación, así como el desarrollo de los mismos y reflejar convenientemente las prioridades medioambientales y climáticas en las políticas y estrategias de financiación para apoyar la cohesión económica, social y territorial" (Idem).

En base a lo anterior proponemos enlazar esta propuesta de diseño de programas de pago por servicios ecosistémicos con otros instrumentos económicos, especialmente con instrumentos financieros (fondos y fideicomisos).

\subsection{Contrato de pago por servicios ambientales}

Es muy necesaria la celebración de un contrato de pago por servicios ambientales entre los beneficiados por estos y la institución que gestione los recursos.

La intención de este contrato es que se establezcan claramente las obligaciones a cargo de los que van a recibir los pagos y que se estipule que el incumplimiento total o parcial de dichas obligaciones conlleve la suspensión de los pagos e incluso la terminación de la relación contractual. 
3.12. Instrumentos complementarios: campaña de comunicación e información

La campaña de comunicación e información es fundamental para el éxito del programa. Dicha campaña debería estar dirigida a todos los sectores involucrados en el programa: tanto los beneficiados por el pago como los obligados a éste, las autoridades y la sociedad en general.

La valoración de los servicios ambientales de la zona debe conllevar, necesariamente que la sociedad esté informada de qué son estos y para qué sirven.

En el caso de que una parte del programa se financie a través de aportaciones voluntarias, por ejemplo, de los turistas, la campaña de comunicación es esencial.

\subsection{Puesta en marcha del Programa}

Para poner en marcha un programa de este tipo es necesario contar con la voluntad política de los gobiernos municipales dentro de los cuales se aplicaría el programa. Es posible hacerlo a través de los Organismos intermunicipales ya existentes, como por ejemplo Organismos de Cuencas o a través de nuevas fórmulas de asociacionismo intermunicipal.

\subsection{Evaluación y vigilancia}

La vigilancia del programa puede realizarse a través de algún Consejo ciudadano creado para tal fin, en el cual también se evalúe periódicamente la pertinencia y utilidad del programa.

Para la evaluación es útil contar con brigadas de voluntarios que revisen el cumplimiento de los objetivos acordados y aceptados por todos.

\subsection{Actualización del programa}

El programa de pago por servicios ambientales deberá ser evaluado periódicamente. La duración de cada etapa puede ser bianual y, después de este plazo será necesario replantear los objetivos y los recursos destinados a los pagos.

\section{CONCLUSIONES}

Primera- Los manglares desempeñan una importante labor en la mitigación de gases de efecto invernadero, función ésta que no ha sido todavía reconocida en la política ambiental mexicana, encontrándose estos ecosistemas en una situación muy vulnerable.

La conservación de los manglares puede alentarse no sólo desde una estrategia normativa, sino también a través del uso de instrumentos económicos que fomenten la internalización de las externalidades ambientales en materia de protección de la atmósfera.

Existen, además, las bases jurídicas dentro de cada uno de los tres niveles de gobierno para el diseño de un pago por servicios atmosféricos de los manglares, los cuales se encuentran contenidos, en muchas ocasiones, dentro de la franja de la zona federal marítimo terrestre de acuerdo a lo que dispone el Reglamento para el uso y aprovechamiento del mar territorial, vías navegables, playas, zona federal marítimo terrestre y terrenos ganados al mar, por lo que su regulación es de competencia federal. Sin embargo, los estados y municipios, en los que se encuentran, tienen un buen número de competencias relacionadas con la gestión de estos importantes recursos ambientales y podrían estar involucrados en alguno de los aspectos del diseño de este instrumento económico

Segunda- Para diseñar un programa de pago por servicios ecosistémicos o ambientales en manglares es necesario, en primer lugar, delimitar claramente la zona sobre la cual se quiere influir a través del programa de pago por servicios ambientales, distinguiendo entre:

- Zona de conservación y restauración.

Es el espacio sobre el cual son necesarias las acciones de conservación y/o de restauración más intensas, es decir la zona objetivo o zona para la cual se diseña el programa.

En esta área se encontrarán normalmente los recursos más vulnerables y asimismo los que brindan un mayor número de servicios ambientales.

En este espacio se identificarán la mayoría de los beneficiados por dicho programa, de acuerdo a su nivel de participación en la conservación de los recursos.

- Zona de aplicación del programa.

Esta zona puede y normalmente será mucho más amplia que la anterior. Puede incluir, por ejemplo, toda la cuenca en la que se encuentre la zona de con- 
servación o simplemente ir más allá del ecosistema a proteger, incluyendo a las demarcaciones políticas relacionadas con el ecosistema.

La zona de aplicación del programa sería la unidad económica, política, ambiental y social relacionada directamente con los manglares a proteger.

Tercera- En segundo lugar es necesario identificar los servicios ambientales específicos brindados por el ecosistema.

Estos servicios deben ser ordenados de acuerdo a su importancia y valor y deben, también, ser clasificados. Es necesario hacer un listado de los grupos beneficiados por los servicios ambientales que brinda el ecosistema sobre el cual estamos trabajando.

Asimismo, es importante distinguir el nivel en el que se pueden encuadrar dichos beneficiados: municipal, estatal, nacional e internacional o global, ya que la estrategia de pago dependerá en gran medida de dichos niveles, los cuales también nos darán las bases legales necesarias para el diseño de este instrumento.

Cuarta- El tradicional principio "quien contamina paga", de acuerdo al cual es el potencial contaminador el que debe cargar con los costes económicos de prevenir y controlar la contaminación, no es el único principio para la distribución de costes, ya que también tiene sentido el principio "quien se beneficia paga", según el cual aquéllos que reciben o esperan recibir beneficios por actividades de control de la contaminación o acciones de conservación deberían pagar por dicho beneficio.

Quinta- En cuarto lugar es necesario determinar quienes son los propietarios o poseedores de los recursos que brindan los servicios ambientales.

Es necesario tomar en cuenta que, en el caso de los manglares, lo habitual es encontrarnos con diferentes regímenes de "tenencia de la tierra". Es habitual que existan tanto terrenos públicos como privados, ejidatarios, propietarios, poseedores, concesionarios... además de que el mismo manglar suele estar sobre espacios que se encuentran, en ocasiones, dentro de la zona federal marítimo terrestre y, en otras, fuera de ésta, con las consecuentes diferencias en los regímenes jurídicos aplicables.
Sexta- El siguiente paso necesario para una propuesta de este tipo se centra en la construcción de unos escenarios hipotéticos de conservación de los recursos de la zona.

Estos escenarios servirán para, posteriormente, establecer los objetivos del programa, los cuales serán la base para el contrato de pago por servicios ambientales entre los beneficiados y quienes pagan dichos servicios.

Después de haber construido estos escenarios hipotéticos y con la finalidad de lograr el más optimista de ellos deben plantearse los objetivos del programa de pago por servicios ambientales. Cada objetivo debe asociarse a un servicio ambiental específico.

Séptima- La siguiente etapa para el diseño del programa de pago por servicios ambientales se centra en identificar claramente quienes deben beneficiarse por el pago, es decir, a quien debería pagarse y porqué. Estos beneficiados por el pago son quienes deberían llevar a cabo las acciones de prevención, conservación y/o restauración necesarias para lograr los objetivos del programa.

Octava- El paso siguiente consiste en determinar quienes deberían pagar los servicios ambientales y cuánto deberían pagar. Este último aspecto, es, quizá, el más complicado en una propuesta de este tipo, pues no es fácil valorar económicamente los recursos naturales, a pesar de que existen diversas metodologías para ello.

Es conveniente agrupar a los sectores sobre los cuales consideramos deberá recaer el pago. Estos sectores tendrán que desprenderse de los beneficiados por los servicios ambientales que brinda el ecosistema y se sugiere ordenarlos o aglutinarlos de acuerdo a los beneficios o servicios recibidos por la conservación de los manglares, tomando en cuenta si son beneficiados directa o indirectamente y teniendo en cuenta, también, su capacidad económica.

Novena- Es necesario diseñar una campaña de comunicación e información dirigida a todos los actores involucrados en el programa que permita la aportación imaginativa de los grupos de interés, que prevenga los conflictos sociales y que dé transparencia al programa. 
Décima- La vigilancia del programa puede realizarse a través de algún Consejo ciudadano creado para tal fin, en el cual también se evalúe periódicamente la pertinencia y utilidad del programa.

\section{REFERENCIAS}

Aranda Ogayar, M. (2001). Método de los escenarios: apuntes teóricos. Obtenido en línea el 7 de abril de 2010. Disponible en: www4.ujaen.es/ - egarcia/programadedirest05-06.doc

Barbier E. B. (2011). Wetlands as natural assets. Hydrological Sciences Journal, 56, (8), pp. 1360-1373.

Benedict, Mark \& McMahon, Edward. (2002). Green infrastructure: smart conservation for the 21 st century. Renewable Resources Journal, 20, (3). Obtenido en línea el 14 de mayo de 2018. Disponible en: http://www. sprawlwatch.org/greeninfrastructure.pdf

Cantó López, María Teresa. (2014). La ordenación de la infraestructura verde en el sudeste ibérico. Cuadernos de Biodiversidad, 45, pp. 10-22. Obtenido en línea el 8 de mayo de 2018. Disponible en: http://cibio.ua.es/ Cuadernos/45/45-3.pdf

Cerón, R.M., Cerón, J.G., Guerra, J.J., Zavala, J.C., Amador, L.E., Endañu, E. \& Moreno, G.J. (2010). Estimación del potencial de captura de carbono en suelos de manglar de isla del Carmen. Unacar-Tecnociencia, 4, (1), pp. 23-39.

Cerón, R.M., Cerón, J.G., Guerra, J.J., Zavala, J.C., Amador, L.E., Endañu, E. \& Moreno, G.J. (2010). Estimación de la tasa de captura de carbono en ecosistemas de manglar asociados al área ecosistemas de manglar asociados al área natural protegida Laguna de Términos. Universidad Autónoma del Carmen. Obtenido en línea el 27 de abril de 2018. Disponible en: respyn2.uanl.mx/especiales/2010/ee-102010/documentos/conferencias/03.pdf

Comisión de las Naciones Unidas Europeas. (2009). Adaptación al cambio climático: Hacia un marco europeo de actuación. Libro blanco COM [2009] 147 final, Libro Blanco, abril 2009.

Comisión Europea. (2014). Construir una infraestructura verde para Europa. Bélgica. Obtenido en línea el 6 de junio de 2018. Disponible en: http://ec.europa.eu/ environment/nature/ecosystems/docs/GI-Brochure 210x210-ES-web.pdf
Comisión Nacional Forestal (CONAFOR) (2014). Programa Nacional Forestal 2014-2018. Publicado en Diario Oficial de la Federación el 28 de diciembre de 2014.

Comisión Nacional para el Conocimiento y uso de la Biodiversidad. (s.f). Servicios Ambientales. Obtenido en línea el 16 de marzo de 2018. Disponible en: http://www. biodiversidad.gob.mx/ecosistemas/serviciosam.html

De Groot, R., Brander, L., Van der Ploeg, S., Costanza, R., Bernard, F., Braat, L., Christie, M., Crossman, N., Ghermandi, A., Hein, L., Hussain, S., Kumar, P., McVittie, A., Portela, R., Rodriguez, L.C., Ten Brink, P., \& Van Beukering, P. (2012). Global estimates of the value of ecosystems and their services in monetary units. Ecosystem Services, 1, (1), pp. 50-61.

El método de los escenarios (2006). Obtenido en línea el 7 de abril del 2010. Disponible en: http://www.innovacion.com.es/index.php?option=com_content\&amptask=view\&id $=175 \&$ Itemid $=34$

European Commission. (2010). Green Infrastructure Implementation Conference. Conference Background. Obtenido en línea el 27 de abril de 2018. Disponible en: http:// ec.europa.eu/environment/nature/ecosystems/docs/ GI\%20programme.pdf

Food and Agriculture Organization (FAO) (2007). The World's Mangroves 1980-2005: A thematic study prepared in the framework of the Global Forest Resources Assessment 2005. Roma: FAO, p.55.

García, T. (2013). Derecho ambiental mexicano. Introducción y principios. México: Editorial Bosch, p. 251.

García, T. (2008). Las cuencas en el Derecho ambiental mexicano: instrumentos para su gestión integral. Boletín Mexicano de Derecho Comparado, 16, (123), pp. 1259-1290.

Gómez, J. (2014). Propuesta Sobre Marco Conceptual, Definición y Clasificación de Servicios Ecosistémicos para el Ministerio del Medio Ambiente. Obtenido en línea el 30 de abril de 2018. Disponible en: http://portal.mma.gob.cl/ wp-content/uploads/2014/10/Propuesta-Marco-Conceptual-Definicion-y-Clasificacion-de-Servicios-Ecosistemicos_V1.0_Baja.pdf

Gutman, P. (1995). Escenarios ecológicos. El futuro ecológico de un continente: Una visión prospectiva de la América Latina. México: Universidad de las Naciones Unidas/ Fondo de Cultura Económica. p. 1126. 
Haines-Young, R. \& Potschin, M. (2011). Report to the Environment Agency. Common International Classification for Ecosystem Services (CICES). Londres: European Environment Agency.

Instituto Nacional de Ecología y Cambio Climático (INECC) (2012). Ley General de Cambio Climático. Publicado en Diario Oficial de la Federación el 6 de junio de 2012.

Kauffman-Boone, J., Donato, D.C. \& Adame, M.F. (2013). Protocolo para la medición, monitoreo y reporte de la estructura, biomasa y reservas de carbono de los manglares. Indonesia: Editorial Cifor.

Lozano, Y. (2007). Los sumideros de carbono: un análisis de la potencialidad económica en un bosque de manglar del pacífico colombiano. Ingeniería de Recursos Naturales y del Ambiente, Universidad del Valle, 6, pp. 82-92.

Manso, R. (2001). Resultado de la estimación de la captura de carbono en cuba entre los años 1989 y 1997. Cuba: Ministerio de Ciencia Tecnología y Medio Ambiente.

Naumann, S., Davis, M., Kaphengst, T., Pieterse, M., Rayment, M. (2011). Design, Implementation and cost elements of Green Infrastructure projects, Final report to the European Commission, DG Environmental, Contract no. 070307/2010/577182/ETU/F.1, Ecologic institute and GHK Consulting.

Park, Chris \& Allaby, Michael (2013). A Dictionary of Environment and Conservation. 2a ${ }^{\mathrm{a}}$. Ed., Reino Unido: Oxford University Press.

Programa de las Naciones Unidas para el Medio Ambiente (PNUMA). (2010). El "Atlas Mundial de los Manglares pone de relieve la importancia de y las amenazas a los manglares". Obtenido en línea el 14 de julio de 2010. Disponible en: http://www.pnuma.org/informacion/ comunicados/2010/14Julio2010bis/1cpb35n_i.htm

Plan Nacional de Desarrollo para el periodo 2007-2012. Publicado en Diario Oficial de la Federación el 31 de mayo de 2007.

Plan Nacional de Desarrollo 2013-2018. Publicado en Diario Oficial de la Federación el 20 de mayo de 2013.

Rasmussen, L. B. (2011). Facilitating Change: Using Interactive methods in organizations, communities and networks. Dinamarca: Polyteknisk Forlag.
Rodríguez-Zúñiga, M.T., Troche-Souza, C., Vázquez-Lule, A. D., Márquez-Mendoza, J. D., Vázquez-Balderas, B., Valderrama-Landeros, L., Velázquez-Salazar, S., Cruz-López, M. I., Ressl, R., Uribe-Martínez, A., Cerdeira-Estrada, S., Acosta-Velázquez, J., Díaz-Gallegos, J., Jiménez-Rosenberg, R., Fueyo-Mac Donald, L. \& Galindo-Leal, C. (2013). Manglares de Méxicol Extensión, distribución y monitoreo. Comisión Nacional para el Conocimiento y Uso de la Biodiversidad (CONABIO). México D.F., p. 128.

Red de Fondos Ambientales de América Latina y el Caribe (RedLAC). Disponible en: http://redlac. org/index.php?option $=$ com_content $\&$ view $=$ article\&id $=100 \&$ Itemid $=119 \&$ lang $=$ es

Ricaño, A. (2017). Propuesta de pago por servicios ambientales en el Sistema Lagunar de Alvarado (Tesis de licenciatura) Universidad Veracruzana, Xalapa, Veracruz, México. pp. 94-111.

Sanjurjo, E. \& Welsh, S. (2005). Una descripción del valor de los bienes y servicios ambientales prestados por los manglares. Gaceta Ecológica, 74, pp. 55-68.

Secretaría de Gobernación (SEGOB) (1991). Reglamento para el uso y aprovechamiento del mar territorial, vías navegables, playas, zona federal maritimo terrestre y terrenos ganados al mar. Publicado el Diario Oficial de la Federación el 21 de agosto de 1991.

Secretaría de Medio Ambiente y Recursos Naturales (SEMARNAT). (s.f.). ¿Qué son los Servicios Ambientales?. Instituto de Ecología. Obtenido en linea el 23 de Julio de 2015. Disponible en: http://www1.inecol.edu. $\mathrm{mx} /$ costasustentable/esp/pdfs/Juegos/Otros/PostalesServiciosAmbientales.pdf

Secretaría de Medio Ambiente y Recursos Naturales (SEMARNAT) (2010). Norma Oficial Mexicana NOM059-SEMARNAT-2010. Protección ambiental- Especies nativas de México de flora y fauna silvestres-Categorías de riesgo y especificaciones para su inclusión, exclusión o cambio-Lista de especies en riesgo. Publicado en Diario Oficial de la Federación el 23 de diciembre de 2010.

Secretaría de Medio Ambiente y Recursos Naturales (SEMARNAT) (2013). Estrategia Nacional de Cambio Climático. Publicado en Diario Oficial de la Federación el 3 de diciembre de 2013.

Secretaría General. Código Penal Federal. Publicado en Diario Oficial de la Federación del 14 de agosto de 1931. 
Suárez, A., Camarena, P., Herrera, I. \& Lot, A. (2011). Infraestructura verde y corredores ecológicos de los pedregales: ecología urbana del sur de la ciudad de México. México: Universidad Nacional Autónoma de México, p. 1.

Ten Brink, P., Russi, D., Farmer, A., Badura, T., Coates, D., Förster J., Kumar, R. \& Davidson, N. (2013). La Economía de los Ecosistemas y la Biodiversidad relativa al agua y los humedales. Resumen ejecutivo.
Yepes, A., Zapata, M., Bolivar, J., Monsalve, A., Espinosa, S.M., Sierra-Correa P.C. \& Sierra A. (2016). Ecuaciones alométricas de biomasa aérea para la estimación de los contenidos de carbono en manglares del Caribe Colombiano. Revista de Biología Tropical, 64, (2), pp. 913-926. Convención Relativa a los Humedales de Importancia Internacional, especialmente como Hábitat de Aves Acuáticas. Ramsar (Irán) (1971). VII Programa general de la Unión Europea en materia de Medio Ambiente. Compilación de Tratados de las Naciones Unidas No 14583. Modificada según el Protocolo de París el 3 de diciembre de 1982, y las Enmiendas de Regina el 28 de mayo de 1987. 

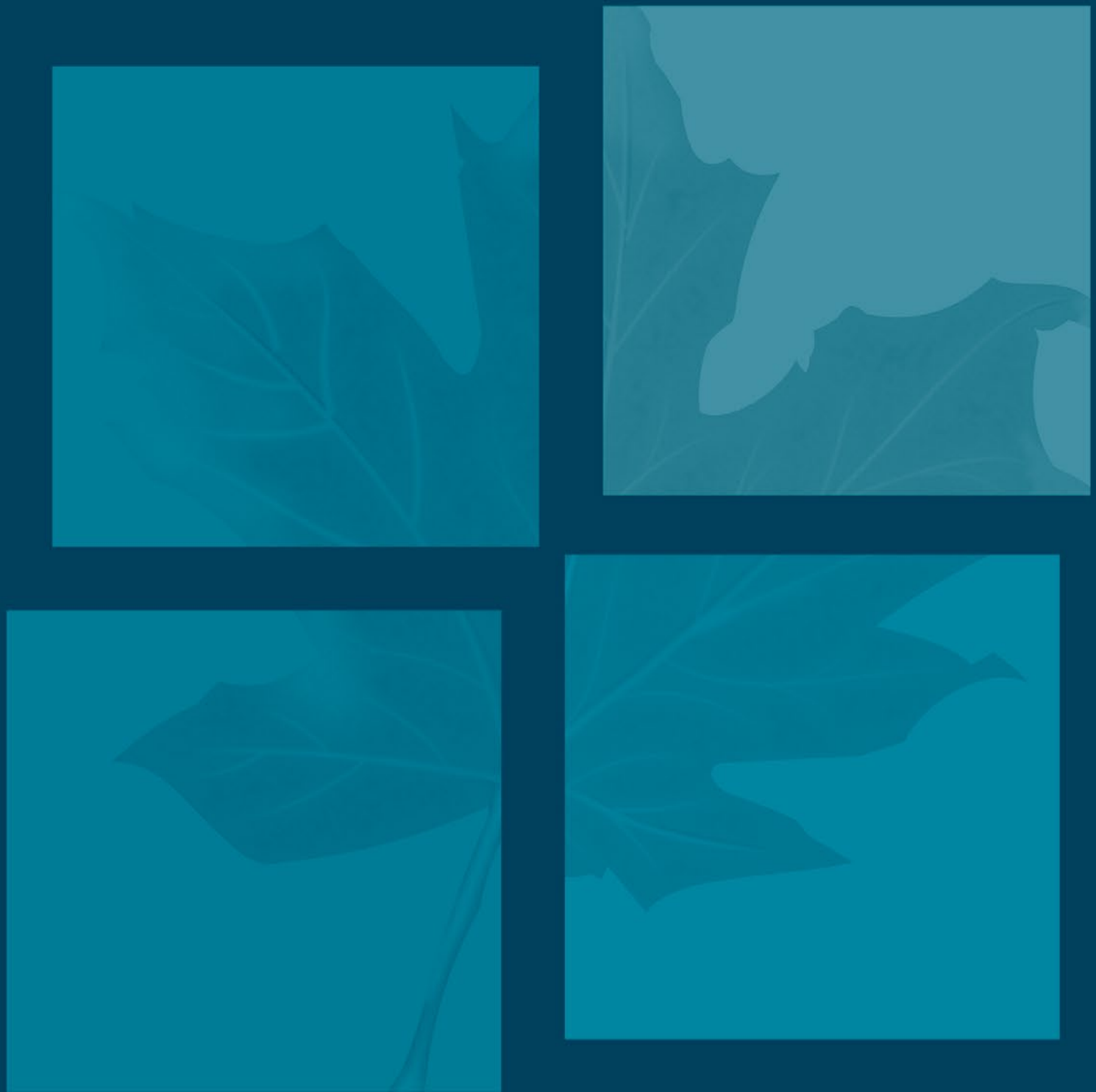